\title{
UVA Radiation Induced Ultrafast Electron Transfer from a Food Carcinogen Benzo[a]pyrene to Organic Molecules, Biological Macromolecules, and Inorganic Nano Structures
}

\author{
Soma Banerjee, ${ }^{\dagger}$ Soumik Sarkar, ${ }^{\dagger}$ Karthik Lakshman, ${ }^{\ddagger}$ Joydeep Dutta, ${ }^{\ddagger}$ and Samir Kumar Pal ${ }^{*}{ }^{\dagger}$ \\ ${ }^{\dagger}$ UNANST, Department of Chemical, Biological \& Macromolecular Sciences, S. N. Bose National Centre for Basic Sciences, Block \\ JD, Sector III, Salt Lake, Kolkata 700 098, India \\ ${ }^{\ddagger}$ Water Research Center, Sultan Qaboos University, P.O. Box 17, 123 Al-Khoudh, Sultanate of Oman
}

\begin{abstract}
Reactions involving electron transfer (ET) and reactive oxygen species (ROS) play a pivotal role in carcinogenesis and cancer biochemistry. Our present study emphasizes UVA radiation induced ET reaction as one of the key aspects of a potential carcinogen, benzo $[a]$ pyrene (BP), in the presence of a wide variety of molecules covering organic $p$ benzoquinone (BQ), biological macromolecules like calfthymus DNA (CT-DNA), human serum albumin (HSA) protein, and inorganic zinc oxide $(\mathrm{ZnO})$ nanorods (NRs).

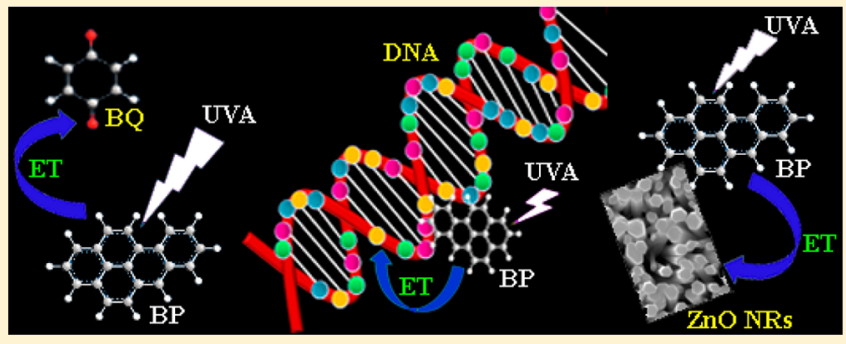
Steady-state and picosecond-resolved fluorescence spectroscopy have been used to monitor such ET reactions. Physical consequences of BP association with CT-DNA have been investigated through temperature-dependent circular dichroism (CD) spectroscopy. The temperature-dependent steady-state, picosecondresolved fluorescence lifetime and anisotropy studies reveal the effect of temperature on the perturbation of such ET reactions from BP to biological macromolecules, highlighting their temperature-dependent association. Furthermore, the electron-donating property of $\mathrm{BP}$ has been corroborated by measuring wavelength-dependent photocurrent in a BP-anchored ZnO NR-based photodevice, offering new physical insights for the carcinogenic study of BP.
\end{abstract}

\section{INTRODUCTION}

Benzo $[a]$ pyrene (BP), a polycyclic aromatic hydrocarbon (PAH), is one of the most potent carcinogens to which people are frequently exposed. ${ }^{1-3}$ Its evolution during fuel and tobacco combustion and presence in grilled and smoked food products has made it the most studied carcinogen since its isolation. ${ }^{3-8}$ The accepted hypothesis for carcinogens is that they are first converted to electrophilic metabolites which react covalently with the nucleophilic DNA. Such DNA adducts are the ultimate molecular lesion leading to the activation of oncogenes and ultimately giving rise to neoplasia. ${ }^{9}$ Earlier studies ${ }^{10}$ indicate the significance of one-electron oxidation as a possible primary step in the chemical carcinogenesis of BP. ET reactions are wellknown for their importance in DNA damage, ${ }^{11}$ and recent findings suggest the role of ultrafast ET in inducing singlestrand and double-strand breaks in DNA through reductive DNA damage. ${ }^{12}$ Previous reports investigating BP-DNA complexes through fluorescence and triplet flash photolysis techniques have proposed that the majority of the fluorescence in these complexes originates from $\mathrm{BP}$ bound to $\mathrm{GC}-\mathrm{GC}$ intercalation sites. ${ }^{13}$ Such conclusions are supported by the relative quenching efficiencies of $\mathrm{BP}$ by mononucleosides dissolved in aqueous ethanol mixtures suggesting 2 '-deoxythymidine as an efficient quencher compared to cytidine, $2^{\prime}$ deoxyguanosine, and adenosine. Furthermore, it has also been reported $^{13}$ that the fluorescence of BP in aqueous BP-DNA complexes gets strongly quenched upon the addition of $\mathrm{Ag}^{+}$ ions which bind predominantly to guanosine in DNA, validating the fact that the fluorescence of $\mathrm{BP}$ in $\mathrm{BP}-\mathrm{DNA}$ complexes originates from GC sites. However, the study does not preclude the possibility of BP binding at AT-rich sites. The same study reports shorter lifetime of BP in DNA complexes compared to that in degassed benzene, suggesting strong fluorescence quenching of BP upon complexation with DNA. $\mathrm{BP}$ fluorescence quenching by nucleoside solutions shows no association between the quencher and BP in the ground state, while a short-lived charge-transfer complex is formed when an excited-state BP collides with a nucleoside. ${ }^{13}$ In such chargetransfer complexes, determination of the electron donor and acceptor is based on the relative ionization potentials and electron affinities of the two molecules forming the complex. The ionization potentials of the aromatic hydrocarbons are generally lower than the nitrogenous bases, ${ }^{13}$ and calculations indicate that pyrimidines are better electron acceptors than purines. However, strong experimental evidence highlighting the electron-transfer (ET) reaction from BP to DNA is still lacking in the current literature.

Earlier studies ${ }^{14}$ report that genotoxic carcinogens interact not only with DNAs but also with proteins. In this regard, serum proteins are particularly important because hepatocytes

Received: December 19, 2012

Revised: March 9, 2013

Published: March 13, 2013 
are not only the cells in which serum proteins are synthesized but also the cells in which most xenobiotic metabolism, including microsomal oxidations which activate carcinogens, takes place. Among serum proteins, serum albumin being abundant and because of its role as a carrier of fatty acids, endobiotics, and xenobiotics, there is a high probability that it will bind and form covalent adducts with ultimate carcinogens. There have been extensive studies on the adduct formation of BP with serum albumin, ${ }^{15,16}$ yet there is no information regarding the ET reaction between the two in the present literature. Moreover, it is of great interest to investigate the effect of temperature on such ET reaction between BP and biological macromolecules like DNA and protein.

Apart from chemical carcinogens, ionizing radiations play a significant role in the induction of cancer. ${ }^{17,18}$ Certain radiations like UVA are also known to cause DNA damage through ET in the presence of certain photosensitizers. ${ }^{19}$ Earlier studies have shown how coexposure to BP and UVA induces double strand breaks (DSBs) in DNA, in both cell-free system (in vitro) and cultured Chinese hamster ovary (CHO$\mathrm{K} 1)$ cells $^{20,21}$ resulting in phototoxicity and photocarcinogenesis. A singlet oxygen scavenger sodium azide $\left(\mathrm{NaN}_{3}\right)$ effectively showed inhibition in the production of DSBs, suggesting singlet oxygen is the principal ROS generated by BP and UVA both in vitro and in vivo. ${ }^{21}$ It has also been suggested that the mechanism of DNA damage by BP in the presence of UVA differs in cell and cell-free systems. In spite of such extensive reports, the exploration of the photophysics lying behind the coexposure of DNA to BP and UVA radiation is lacking in the literature to the best of our knowledge.

Recently, an ultrasensitive photoelectrochemical immunoassay comprising bifunctional gold nanoparticles modified with PAH antigen and horseradish peroxidise (HRP) on nanostructured $\mathrm{TiO}_{2}$ electrode decorated with antibodies has been proposed as a means to quantify $\mathrm{PAH}$, based on the changes in photocurrent with respect to the control (without PAH). ${ }^{22}$ However, studies emphasizing the application of nanostructurebased photodevices in the detection of ET reaction, where flow of electrons can be directly monitored in the form of photocurrent, are sparse in the literature.

In our present study, we have used a well-known electron acceptor, ${ }^{23}$-benzoquinone (BQ), as an organic molecule to emphasize the electron-donating efficiency of BP upon excitation with UVA radiation, using a laser source of 375 $\mathrm{nm}$. Both DNA and protein have been used as biological macromolecules to monitor the ET from $\mathrm{BP}$ in presence of UVA radiation. In addition, we have used zinc oxide $(\mathrm{ZnO})$ nanorods (NRs)-based photodevice to directly monitor such photoinduced ET reaction from BP to the NRs. In order to study ET reaction from BP to organic molecules and macromolecules along with inorganic NRs, we have used both steady-state and picosecond-resolved fluorescence spectroscopy. Structural perturbation of DNA in the presence of BP has been investigated through temperature-dependent circular dichroism (CD) spectroscopy. Furthermore, to monitor the effect of temperature on ET from BP to biological macromolecules, we have performed temperature-dependent steadystate and time-resolved fluorescence spectroscopic studies.

\section{EXPERIMENTAL SECTION}

2.1. Sample Preparation. All chemicals used in this study were of analytical grade and were used without any further purification. Solutions of benzo[a]pyrene (BP, obtained from
Sigma) and $p$-benzoquinone $(\mathrm{BQ}$, from Fluka) were prepared in dimethyl sulfoxide (DMSO, from Spectrochem). Calf thymus-DNA (CT-DNA) was obtained from Sigma and all the DNA samples were prepared in $0.05 \mathrm{M}$ phosphate buffer to maintain its double helix structure. ${ }^{24}$ Human serum albumin (HSA, from Sigma) solutions were all prepared in $0.01 \mathrm{M}$ phosphate buffer. In the present study, DNA concentration is expressed in terms of base pair concentration. Both nucleotide and protein concentrations were determined by absorption spectroscopy using the average extinction coefficient per nucleotide of the DNA as $6600 \mathrm{M}^{-1} \mathrm{~cm}^{-1}$ at $260 \mathrm{~nm}^{25}$ and $36500 \mathrm{M}^{-1} \mathrm{~cm}^{-1}$ at $280 \mathrm{~nm}$ for HSA. ${ }^{26} \mathrm{BP}-\mathrm{DNA}$ complexes were prepared as per the methodology reported previously ${ }^{13}$ by Geacintov et al. In the fluorescence experiments of BP and CTDNA, concentration of BP was $1 \mu \mathrm{M}$ while that of CT-DNA was $1 \mathrm{mM}$. For performing temperature-dependent circular dichroism (CD) experiments, concentration of DNA was maintained at $10 \mu \mathrm{M}$. The concentrations of BP and HSA used in the fluorescence experiments were 1 and $200 \mu \mathrm{M}$, respectively.

2.2. Preparation of $\mathrm{BP}-\mathrm{ZnO}$-Based Photodevice. Detailed processes for the hydrothermal growth of the single crystalline $\mathrm{ZnO}$ NRs are described in our previous reports. ${ }^{27,28}$ Briefly, a $1 \mathrm{mM}$ Zinc acetate dihydrate, $\mathrm{Zn}\left(\mathrm{CH}_{3} \mathrm{COO}\right)_{2} \cdot 2 \mathrm{H}_{2} \mathrm{O}$ (Merck), solution in isopropanol was used to prepare the $\mathrm{ZnO}$ seed layer on a fluorinated tin oxide (FTO) substrate followed by annealing in air at $350{ }^{\circ} \mathrm{C}$ for $5 \mathrm{~h}$. A $20 \mathrm{mM}$ aqueous solution of zinc nitrate hexahydrate, $\mathrm{Zn}\left(\mathrm{NO}_{3}\right)_{2} \cdot 6 \mathrm{H}_{2} \mathrm{O}$ (SigmaAldrich), and hexamethylenetetramine, $\mathrm{C}_{6} \mathrm{H}_{12} \mathrm{~N}_{4}$ (Aldrich), was used as a precursor solution for $\mathrm{ZnO} \mathrm{NR}$ growth and the seeded FTO substrates were dipped into it at $90{ }^{\circ} \mathrm{C}$ for $40 \mathrm{~h}$. As-grown $\mathrm{ZnO} \mathrm{NRs}$ on the FTO substrates were then taken out from the precursor solution and rinsed with deionized (DI) water several times to remove unreacted residues from the substrate. Finally, the substrates with $\mathrm{ZnO}$ NRs were annealed at $350{ }^{\circ} \mathrm{C}$ for $1 \mathrm{~h}$ in air and dipped into $3.9 \mathrm{mM}$ DMSO solution of BP and kept in the dark. After $24 \mathrm{~h}$ the photoelectrodes were removed from the BP solution and rinsed several times with DMSO in order to remove weakly adsorbed dye molecules. Since BP does not have any functional group through which it can bind to inorganic NRs, the only possible way of binding is physisorption. Platinized FTO glass was used as a counter electrode where a thin platinum layer was deposited on FTO-coated glass substrates by thermal decomposition of platinum chloride, $\mathrm{H}_{2} \mathrm{PtCl}_{6} \cdot \mathrm{H}_{2} \mathrm{O}$ (Fluka), at $385{ }^{\circ} \mathrm{C}$ for $15 \mathrm{~min}$. The counter electrode was then placed on top of the photoelectrode and a single layer of $50 \mu \mathrm{m}$ thick Surlyn 1702 (Dupont) was used as a spacer between the two electrodes. The photodevices were then sealed and filled with the liquid electrolyte, consisting of $0.5 \mathrm{M}$ lithium iodide (LiI), $0.05 \mathrm{M}$ iodine $\left(\mathrm{I}_{2}\right)$, and $0.5 \mathrm{M}$ 4-tert-butylpyridine (TBP) in acetonitrile (ACN), through two small holes $(\phi=1 \mathrm{~mm})$ drilled on the counter electrode. Finally, the two holes were sealed by Surlyn to prevent electrolyte leakage. A control $\mathrm{ZnO}$ NR photoelectrode without BP was also prepared for comparison.

2.3. Steady-State and Time-Resolved Measurements. Steady-state absorption and emission were measured with Shimadzu Model UV-2450 spectrophotometer and Jobin Yvon Model Fluoromax-3 fluorimeter respectively. CD measurements were carried out on a JASCO 815 spectro-polarimeter with a temperature controller attachment. The scan speed of the measurements was $50 \mathrm{~nm} / \mathrm{min}$ and each spectrum was the 
average of five scans. For baseline correction, CD measurement for buffer solution, in which DNA was prepared, was subtracted from those of the DNA samples. Scanning electron microscope (SEM, JEOL JSM-6301F, operating at $20 \mathrm{kV}$ ) was used to study the morphology of the as-grown $\mathrm{ZnO}$ NRs.

All picosecond transients were measured by using commercially available (Edinburgh Instrument, UK) picosecond-resolved time correlated single-photon-counting (TCSPC) setup (instrument response function, IRF of 80 ps) using $375 \mathrm{~nm}$ excitation laser source with temperature control setup from Julabo (model F32). Fluorescence from the sample was detected by a photomultiplier after dispersing through a double grating monochromator. For all transients the polarizer in the emission side was adjusted to be at $54.7^{\circ}$ (magic angle) with respect to the polarization axis of the excitation beam. Time-resolved study of $\mathrm{BP}-\mathrm{ZnO}$ adduct was done on thin film where $\mathrm{ZnO}$ NRs grown on quartz plates by following the same procedure described in section 2.2. For fluorescence anisotropy $(r(t))$ measurements, emission polarization was adjusted to be parallel or perpendicular to that of the excitation and the anisotropy is defined as

$$
r(t)=\left[I_{\text {para }}-G I_{\text {perp }}\right] /\left[I_{\text {para }}+2 G I_{\text {perp }}\right]
$$

The magnitude of $G$, the grating factor of the emission monochromator of the TCSPC system, was found by longtime tail matching technique. ${ }^{29}$

2.4. Data Analysis. Curve fitting of observed fluorescence transients was carried out using a nonlinear least-squares fitting procedure to a function $\left(X(t)=\int_{0}^{t} E\left(t^{\prime}\right) R\left(t-t^{\prime}\right) \mathrm{d} t^{\prime}\right)$ composed of convolution of the IRF $(E(t))$ with a sum of exponentials $\left(R(t)=A+\sum_{i-1}^{N} B_{i} \mathrm{e}^{-t / \tau_{i}}\right)$ with pre-exponential factors $\left(B_{i}\right)$, characteristic lifetimes $\left(\tau_{\mathrm{i}}\right)$, and a background $(A)$. Relative concentration in a multiexponential decay is expressed as

$$
c_{n}=\frac{B_{n}}{\sum_{i=1}^{N} B_{i}} \times 100
$$

The average lifetime (amplitude-weighted) of a multiexponential decay ${ }^{30}$ is expressed as

$$
\tau_{\mathrm{av}}=\sum_{i=1}^{N} c_{i} \tau_{i}
$$

After the deconvolution, obtained time constants which are one-fourth of the IRF may be reliably reported within the signal-to-noise ratio of the fluorescence transients.

\section{RESULTS AND DISCUSSION}

Figure 1a shows the steady-state fluorescence quenching of benzo $[a]$ pyrene $(\mathrm{BP})$ in DMSO with increasing concentration of $p$-benzoquinone (BQ), which is a well-known electron acceptor. $^{23,31}$ The fluorescence spectrum of BP in the absence of the quencher strongly corroborates with the spectral nature of $\mathrm{BP}$ emission reported earlier in different solvents. ${ }^{32}$ While $\mathrm{BP}$ monomers produce three well-characterized emission peaks around 410, 430, and $455 \mathrm{~nm}$ and a weak band near $485 \mathrm{~nm}$ due to different vibrational bands, BP aggregates are known to produce an emission feature that peaks around $490 \mathrm{~nm} .^{32}$ Since a very low concentration of $\mathrm{BP}(1 \mu \mathrm{M})$ has been used in our sample, the contribution of aggregates does not appear to be significant. The observed decrease in fluorescence intensity of $\mathrm{BP}$ in the presence of BQ can arise either due to collisional/ dynamic or static quenching or both or even through

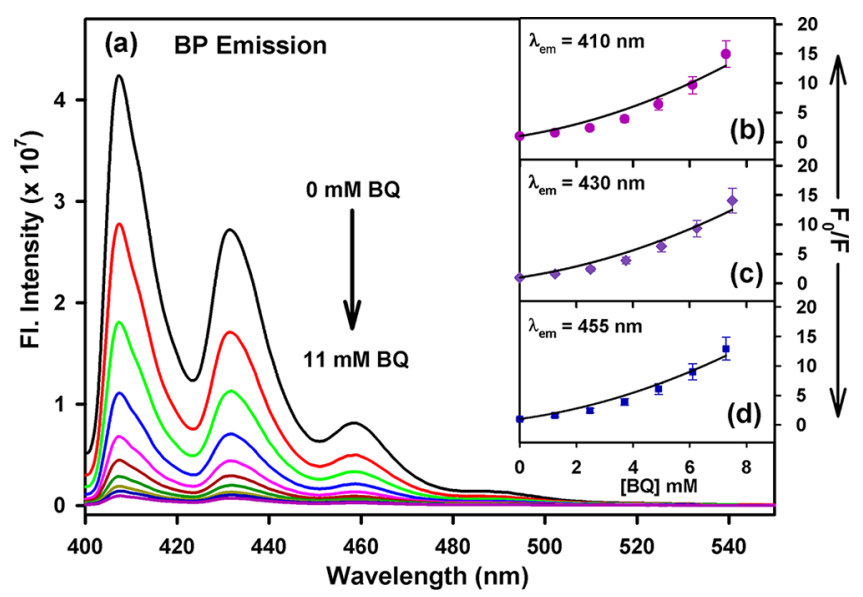

Figure 1. (a) Fluorescence quenching spectra of $1 \mu \mathrm{M}$ benzo[a]pyrene (BP) in DMSO with increasing concentrations of benzoquinone (BQ) $(0,1.25,2.50,3.75,5.0,6.25,7.5,8.75,10$, and $11 \mathrm{mM})$. Plots of $F_{0} / F$ vs BQ concentration at $410 \mathrm{~nm}$ (b), $430 \mathrm{~nm}$ (c), and 455 $\mathrm{nm}(\mathrm{d}) . F_{0}$ and $F$ represent fluorescence intensity of the fluorophore (BP) in the absence and presence of the quencher (BQ), respectively. Excitation wavelength $\left(\lambda_{\mathrm{ex}}=375 \mathrm{~nm}\right)$.

nonmolecular mechanisms where fluorophore itself or other absorbing species attenuates the incident light. ${ }^{30}$ For a better insight on the mechanism of the observed quenching, the relative change in fluorescence intensity of BP has been plotted as a function of the quencher (BQ) concentration at the different vibronic peaks of 410,430 , and $455 \mathrm{~nm}$ as shown in Figure 1, b, c, and d, respectively. For collisional quenching, the decrease in fluorescence intensity is described by the wellknown Stern-Volmer (SV) equation ${ }^{30}$

$$
\frac{F_{0}}{F}=1+k_{\mathrm{q}} \tau_{0}[\mathrm{Q}]=1+K_{\mathrm{SV}}[\mathrm{Q}]
$$

$F_{0}$ and $F$ are the fluorescence intensities in the absence and presence of quencher, respectively; $k_{\mathrm{q}}$ is the bimolecular quenching constant; $\tau_{0}$ is the lifetime of the fluorophore in the absence of quencher, and $[\mathrm{Q}]$ is the concentration of quencher. The Stern-Volmer quenching constant is given by $K_{\mathrm{SV}}=k_{\mathrm{q}} \tau_{0}$. In the case of dynamic quenching, the SV plot $\left(F_{0} / F\right.$ vs [Q]) becomes linear with an intercept of one on the $y$-axis and a slope equivalent to the dynamic quenching constant $\left(K_{\mathrm{D}}\right){ }^{30}$ However, as evident from Figure 1, b, c, and d, the SV plots for the fluorescence quenching of $\mathrm{BP}$ by $\mathrm{BQ}$ (monitored at different wavelengths) appear as an upward curvature, concave toward the $y$-axis. Such curved SV plots are typical for fluorophores which are quenched simultaneously by collisions (dynamic quenching) and nonfluorescent ground-state complex formation (static quenching) with the same quencher. ${ }^{30}$ When both static and dynamic quenching occur for the same fluorophore, the SV equation gets modified as ${ }^{30}$

$$
\frac{F_{0}}{F}=\left(1+K_{\mathrm{D}}[\mathrm{Q}]\right)\left(1+K_{\mathrm{S}}[\mathrm{Q}]\right)
$$

where $K_{S}$ represents the static quenching constant. The modified form of the SV equation, being second order in [Q], accounts for the upward curvature in our SV plots shown in Figure $1 b-d$.

The dynamic portion of the observed quenching has been determined by lifetime measurements. Fluorescence transients of $\mathrm{BP}$ in the absence and presence of different concentrations of 


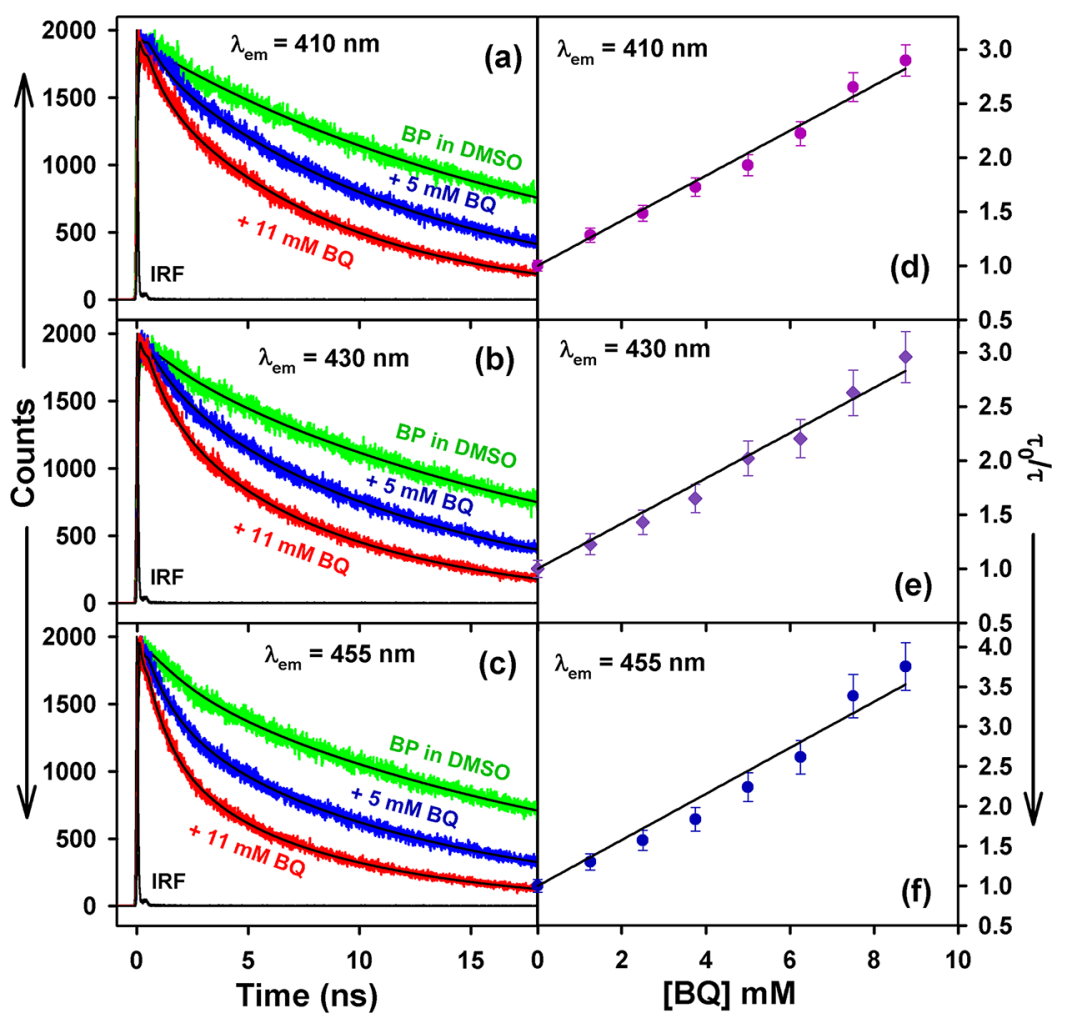

Figure 2. Picosecond-resolved fluorescence transients of BP in DMSO in the absence and presence of different BQ concentrations and the corresponding plots of $\tau_{0} / \tau$ vs BQ concentration monitored at $\left(\lambda_{\text {em }}\right) 410 \mathrm{~nm}(\mathrm{a}, \mathrm{d}), 430 \mathrm{~nm}(\mathrm{~b}, \mathrm{e})$, and $455 \mathrm{~nm}(\mathrm{c}, \mathrm{f}) . \tau_{0}$ and $\tau$ represent lifetimes of the fluorophore (BP) in the absence and presence of the quencher $(\mathrm{BQ})$, respectively. Excitation wavelength $\left(\lambda_{\mathrm{ex}}=375 \mathrm{~nm}\right)$.

BQ monitored at 410, 430, and $455 \mathrm{~nm}$ are presented in Figure $2, a, b$, and $c$, respectively. The lifetime components of the transients are tabulated in Table 1 . As evident from Table 1, a fast component of $2 \mathrm{~ns}$ appears in the fluorescence transients of $\mathrm{BP}$ at emission wavelengths of 430 and $455 \mathrm{~nm}$ both in the absence and in the presence of the quencher, which accounts for the presence of some BP aggregates in the experimental solution, having higher contribution at $455 \mathrm{~nm}$ compared to that at $430 \mathrm{~nm}$, while at $410 \mathrm{~nm}$ the fluorescence originates essentially from the BP monomers. Furthermore, it has also been observed that the contribution of the $2 \mathrm{~ns}$ component in the fluorescence transient of $\mathrm{BP}$ enhances with the increase in $\mathrm{BP}$ concentration due to the progressive formation of $\mathrm{BP}$ aggregates. As BP monomers are known to produce a weak band near $485 \mathrm{~nm},{ }^{32}$ at $490 \mathrm{~nm}$ both the emission from BP monomers and BP aggregates have significant contribution. However, as expected, the 2 ns component (due to BP aggregates) is found to have higher contribution (27\%) in the fluorescence transient of BP at $490 \mathrm{~nm}$ compared to that at 430 (7\%) or $455 \mathrm{~nm}(15 \%)$. The relative contribution of $2 \mathrm{~ns}$ component in the fluorescence transients of BP further increases at $520(31 \%)$ and $560 \mathrm{~nm}(33 \%)$, due to the relatively higher contribution of BP aggregates (data not shown). For dynamic quenching, the average lifetimes in the absence $\left(\tau_{0}\right)$ and presence $(\tau)$ of quencher are given by ${ }^{30}$

$$
\frac{\tau_{0}}{\tau}=1+k_{\mathrm{q}} \tau_{0}[\mathrm{Q}]=1+K_{\mathrm{D}}[\mathrm{Q}]
$$

The numerical values of $\tau_{0}$ and $\tau$ at three different wavelengths are given in Table 1. $\tau_{0}$ values are obtained as 19.32, 18.75, and $17.53 \mathrm{~ns}$ at 410,430 , and $455 \mathrm{~nm}$, respectively. Plots of $\tau_{0} / \tau$ vs quencher concentrations for the lifetime quenching of BP with increasing concentrations of BQ yield a straight line with an intercept of one as shown in Figure 2, d, e, and f, for emission wavelengths $\left(\lambda_{\text {em }}\right) 410,430$, and $455 \mathrm{~nm}$, respectively. The $K_{\mathrm{D}}$ values are obtained as $0.21 \pm 0.01,0.21 \pm 0.01$, and $0.29 \pm 0.02$ $\mathrm{mM}^{-1}$ and the corresponding values of $k_{\mathrm{q}}$ are $10.87 \times 10^{9}$, $11.20 \times 10^{9}$, and $16.54 \times 10^{9} \mathrm{M}^{-1} \mathrm{~s}^{-1}$ while monitoring lifetime quenching at 410,430 , and $455 \mathrm{~nm}$, respectively. The $k_{\mathrm{q}}$ values obtained for BP are comparable to that of hypericin fluorescence quenching by the same quencher $\mathrm{BQ}$, reported previously. ${ }^{33}$ As shown in Figure 1, b, c and d, upon fitting the plots of $F_{0} / F$ vs $[\mathrm{Q}]$ with eq 2 considering the $K_{\mathrm{D}}$ values obtained from time-resolved studies, the values of $K_{\mathrm{S}}$ obtained at 410,430 , and $455 \mathrm{~nm}$ are $0.57 \pm 0.08,0.51 \pm 0.08$, and 0.38 $\pm 0.06 \mathrm{mM}^{-1}$, respectively. The quenching in lifetime being a measure of the rate process that depopulates the excited state can arise either due to energy transfer or electron-transfer (ET) reactions. Since there is no overlap between the emission spectrum of $\mathrm{BP}$ and the absorption spectrum of $\mathrm{BQ}$, the possibility of energy transfer from BP to BQ can be neglected, attributing the quenching to ET reactions. As evident from Table 1 , at low quencher concentrations $(1.25,2.50$, and 3.75 $\mathrm{mM}$ ) the fluorescence transients of BP exhibit an ultrafast component around 500 ps while at higher $\mathrm{BQ}$ concentrations $(5-11 \mathrm{mM})$ the fluorescence transients of the same exhibit two ultrafast components $(\sim 100$ and $\sim 800 \mathrm{ps})$ comparable to the ET components reported earlier in porphyrin-BQ models separated by different distances. ${ }^{34}$ Such multiple ET components in the fluorescence transients of BP at different $\mathrm{BQ}$ concentrations strongly corroborate the nonexponential nature of ET reactions and those components are attributed to the various modes of association (side to side or face to face) along with the different distances between $\mathrm{BP}$ and $\mathrm{BQ}$ in the 
Table 1. Lifetime Components of BP at Its Characteristic Emission Peaks in the Presence of Different Quencher (BQ) Concentrations $([\mathrm{Q}])^{a}$

\begin{tabular}{|c|c|c|c|c|c|c|c|}
\hline$[\mathrm{Q}](\mathrm{mM})$ & $\lambda_{\mathrm{em}}(\mathrm{nm})$ & $\tau_{1}(\mathrm{~ns})$ & $\tau_{2}(\mathrm{~ns})$ & $\tau_{3}(\mathrm{~ns})$ & $\tau_{4}(\mathrm{~ns})$ & $\tau_{\mathrm{av}}(\mathrm{ns})$ & $\tau_{0} / \tau$ \\
\hline \multirow[t]{3}{*}{0.00} & 410 & $19.32(100 \%)$ & & & & 19.32 & 1.00 \\
\hline & 430 & $2.00(7 \%)$ & $20.01(93 \%)$ & & & 18.75 & 1.00 \\
\hline & 455 & $2.00(15 \%)$ & $20.27(85 \%)$ & & & 17.53 & 1.00 \\
\hline \multirow[t]{3}{*}{1.25} & 410 & $0.50(10 \%)$ & $16.67(90 \%)$ & & & 15.05 & 1.28 \\
\hline & 430 & $0.50(4 \%)$ & $2.00(9 \%)$ & $17.32(87 \%)$ & & 15.27 & 1.23 \\
\hline & 455 & $0.50(8 \%)$ & $2.00(16 \%)$ & $17.24(76 \%)$ & & 13.46 & 1.30 \\
\hline \multirow[t]{3}{*}{2.50} & 410 & $0.5(12 \%)$ & $14.72(88 \%)$ & & & 13.01 & 1.49 \\
\hline & 430 & $0.50(6 \%)$ & $2.00(10 \%)$ & $15.34(84 \%)$ & & 13.12 & 1.43 \\
\hline & 455 & $0.50(12 \%)$ & $2.00(18 \%)$ & $15.33(70 \%)$ & & 11.15 & 1.57 \\
\hline \multirow[t]{3}{*}{3.75} & 410 & $0.5(16 \%)$ & $13.22(84 \%)$ & & & 11.19 & 1.73 \\
\hline & 430 & $0.50(6 \%)$ & $2.00(14 \%)$ & $13.83(80 \%)$ & & 11.37 & 1.65 \\
\hline & 455 & $0.50(14 \%)$ & $2.00(20 \%)$ & $13.76(66 \%)$ & & 9.55 & 1.84 \\
\hline \multirow[t]{3}{*}{5.00} & 410 & $0.10(4 \%)$ & $0.80(14 \%)$ & $12.06(82 \%)$ & & 10.01 & 1.93 \\
\hline & 430 & $0.10(8 \%)$ & $0.80(8 \%)$ & $2.00(12 \%)$ & $12.46(72 \%)$ & 9.28 & 2.02 \\
\hline & 455 & $0.10(9 \%)$ & $0.80(13 \%)$ & $2.00(19 \%)$ & $12.42(59 \%)$ & 7.82 & 2.24 \\
\hline \multirow[t]{3}{*}{6.25} & 410 & $0.10(8 \%)$ & $0.80(15 \%)$ & $11.13(77 \%)$ & & 8.70 & 2.22 \\
\hline & 430 & $0.10(8 \%)$ & $0.80(8 \%)$ & $2.00(13 \%)$ & $11.52(71 \%)$ & 8.51 & 2.20 \\
\hline & 455 & $0.10(11 \%)$ & $0.80(15 \%)$ & $2.00(20 \%)$ & $11.42(54 \%)$ & 6.70 & 2.62 \\
\hline \multirow[t]{3}{*}{7.50} & 410 & $0.05(14 \%)$ & $0.80(16 \%)$ & $10.22(70 \%)$ & & 7.29 & 2.65 \\
\hline & 430 & $0.05(14 \%)$ & $0.80(9 \%)$ & $2.00(13 \%)$ & $10.62(64 \%)$ & 7.14 & 2.63 \\
\hline & 455 & $0.05(21 \%)$ & $0.80(18 \%)$ & $2.00(16 \%)$ & $10.46(45 \%)$ & 5.18 & 3.38 \\
\hline \multirow[t]{3}{*}{8.75} & 410 & $0.05(15 \%)$ & $0.90(17 \%)$ & $9.57(68 \%)$ & & 6.67 & 2.90 \\
\hline & 430 & $0.05(15 \%)$ & $0.80(12 \%)$ & $2.00(12 \%)$ & $9.83(61 \%)$ & 6.34 & 2.96 \\
\hline & 455 & $0.05(21 \%)$ & $0.80(20 \%)$ & $2.00(16 \%)$ & $9.72(43 \%)$ & 4.67 & 3.75 \\
\hline \multirow[t]{3}{*}{10.0} & 410 & $0.04(20 \%)$ & $0.80(17 \%)$ & $8.84(63 \%)$ & & 5.71 & 3.38 \\
\hline & 430 & $0.04(21 \%)$ & $0.80(11 \%)$ & $2.00(13 \%)$ & $9.23(55 \%)$ & 5.43 & 3.45 \\
\hline & 455 & $0.04(26 \%)$ & $0.80(20 \%)$ & $2.00(18 \%)$ & $9.20(36 \%)$ & 3.84 & 4.57 \\
\hline \multirow[t]{3}{*}{11.0} & 410 & $0.04(21 \%)$ & $0.80(18 \%)$ & $8.34(61 \%)$ & & 5.24 & 3.69 \\
\hline & 430 & $0.04(18 \%)$ & $0.80(15 \%)$ & $2.00(13 \%)$ & $8.68(54 \%)$ & 5.07 & 3.70 \\
\hline & 455 & $0.04(28 \%)$ & $0.80(21 \%)$ & $2.00(18 \%)$ & $8.61(33 \%)$ & 3.38 & 5.19 \\
\hline
\end{tabular}

${ }^{a} \lambda_{\mathrm{em}}$ represents the emission wavelength. $\tau$ represents the time constant in nanoseconds, and the numbers in parentheses represent the relative contributions of the components. $\tau_{\mathrm{av}}$ represents the average lifetime in nanoseconds and is equivalent to $\tau_{0}$ at $[\mathrm{Q}]=0 . \tau_{\mathrm{av}}=\tau$ at $[\mathrm{Q}] \neq 0$. Error $\pm 5 \%$.

solvent which control the ET rates. ${ }^{34}$ As evident from earlier studies, ${ }^{31}$ BQ has a positive electron affinity of $1.89 \mathrm{eV}$ and forms a stable negative ion through charge-transfer collisions. Furthermore, pyrene class of molecules is known to have a lower electron affinity $(0.59 \mathrm{eV})^{35}$ compared to BQ which further supports the ET from BP to BQ leading to the observed quenching in the fluorescence lifetime of BP with increasing BQ concentrations.

Upon monitoring the ET reaction from $\mathrm{BP}$ to $\mathrm{BQ}$ molecule as shown in Scheme 1a, another macromolecule, calf-thymus DNA (CT-DNA), has been considered to investigate the mode of interaction between BP and CT-DNA upon exciting the former with UVA radiation (Scheme $1 \mathrm{~b}$ ). It has to be noted that, as CT-DNA absorbs weakly above $300 \mathrm{~nm},{ }^{36}$ it will have negligible effect on the emission property of BP upon exciting the solution of BP-CT-DNA complex at $375 \mathrm{~nm}$. Figure 3a shows the temperature-dependent fluorescence spectra of BPCT-DNA complex. Emission spectra of BP in the presence of CT-DNA show that the relative emission intensities of BP at the resolved peaks $(410,430$, and $455 \mathrm{~nm}$ ) are much higher compared to that of the aggregate peak around $490 \mathrm{~nm}$. The relatively lower emission intensity of the aggregate peak compared to that of the monomer BP peaks in the presence of CT-DNA is a clear evidence of association between the two, particularly at low temperatures where the solubility of BP in aqueous medium is negligible being at around $10^{-8} \mathrm{M}$. As shown in the Figure 3a, the emission intensities of BP in CTDNA enhance with the increase in temperature. Figure $3 a$ inset shows the emission intensities of the same, monitored at 410 $\mathrm{nm}$ as a function of temperature, where the enhancement in the emission intensity appears to initiate at about $25{ }^{\circ} \mathrm{C}$. To selectively monitor the interaction between $\mathrm{BP}$ monomers and the CT-DNA, fluorescence transients have been monitored at $410 \mathrm{~nm}$ where the contribution of BP aggregates is minimum or negligible. Figure $3 \mathrm{~b}$ shows the picosecond-resolved fluorescence transients of BP-CT-DNA complex at 20 and $87^{\circ} \mathrm{C}$. The purpose of choosing high temperature around 87 ${ }^{\circ} \mathrm{C}$ was to attain the melting temperature of genomic DNA, which has earlier been reported ${ }^{37}$ to be $83{ }^{\circ} \mathrm{C}$. The corresponding lifetime components of the complex have been tabulated in Table 2. The ultrafast time components of 50 and 900 ps, being comparable with the ET components observed in the fluorescence transient of BP undergoing ET reaction with $\mathrm{BQ}$, are attributed to the UVA radiation induced ET between $\mathrm{BP}$ and DNA. Ionization potential of aromatic hydrocarbons being lower than the nitrogenous bases in $\mathrm{DNA}^{13}$ and pyrimidines being better electron acceptors than purines, it can be concluded that, in the ET complex between BP and CTDNA, electron flows from BP to DNA through the pyrimidine bases. As evident from Figure $3 \mathrm{~b}$ and Table 2, the relative contribution of the ET components of 50 and 900 ps decreases from 40 to $4 \%$ and from 33 to $11 \%$, respectively, with the 
Scheme 1. UVA Radiation Induced Electron Transfer (ET) from Benzo[a]pyrene (BP) to (a) Organic Molecule, Benzoquinone (BQ), and (b) Biological Macromolecule, DNA. (c) Schematic Representation of a Model ZnO NR (gray)-Based Photodevice ${ }^{a}$
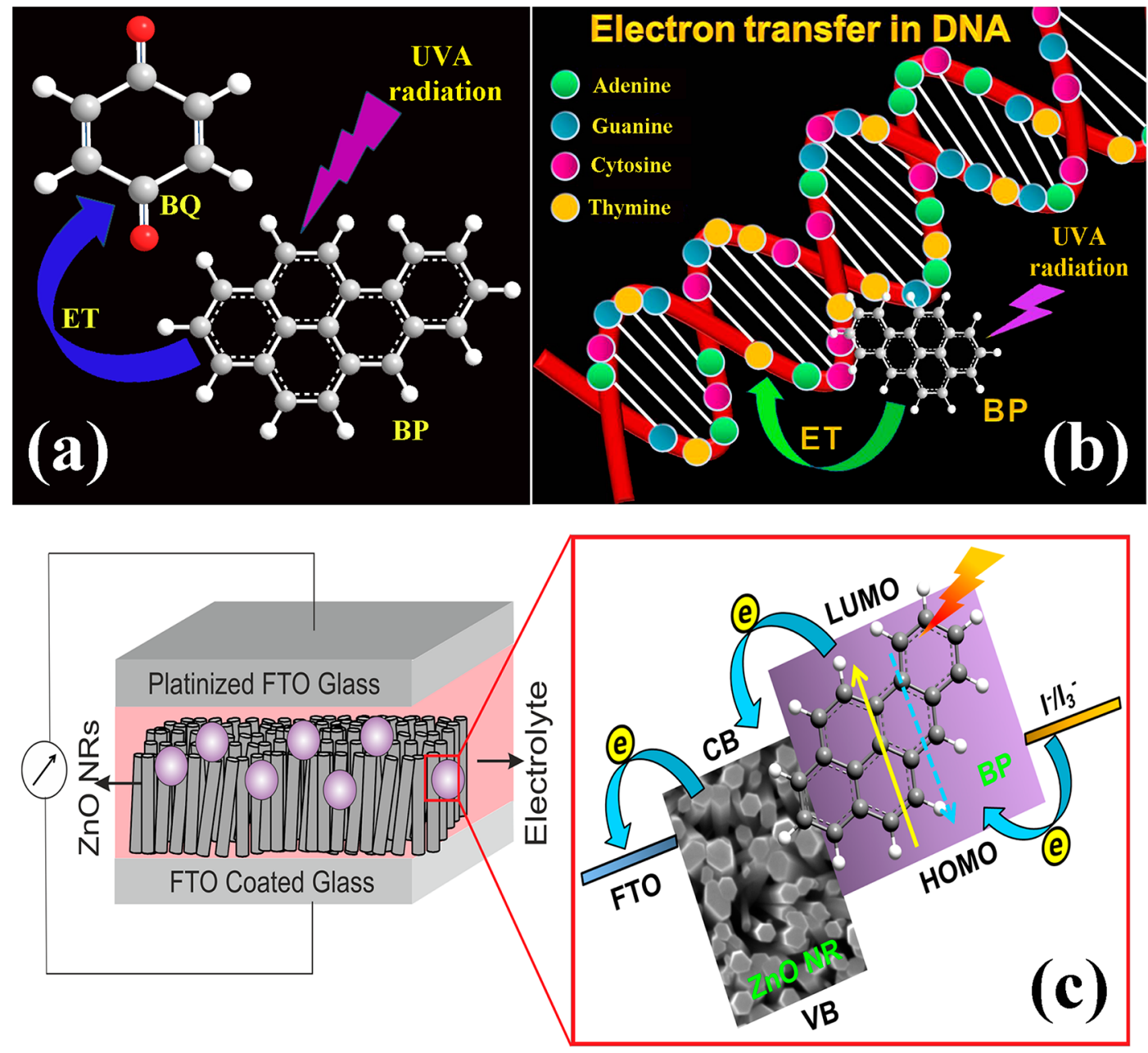

${ }^{a} \mathrm{BP}$ (purple) molecules are anchored on ZnO NRs (gray rods) by surface adsorption. The charge separation and interparticle charge migration processes of the entire photodevice structure are shown.

increase in temperature from 20 to $87^{\circ} \mathrm{C}$. The time-resolved studies strongly corroborate with the temperature-dependent steady-state emission results of BP in CT-DNA as shown in Figure 3a, endorsing the fact that, with the melting of DNA, the ET pathway from BP to DNA gets interrupted, resulting in the enhancement of emission intensity of BP along with its excitedstate lifetime. The interruption in ET pathway from BP to DNA with the DNA melting can arise either due to the release of BP from DNA or due to the binding of BP to single-stranded DNA in an orientation unfavorable for ET. As evident from Figure $3 \mathrm{~b}$ and Table 2, the fluorescence transient of BP in CTDNA at $87{ }^{\circ} \mathrm{C}$ can be fitted triexponentially with time components of 100 ps (4\%), 800 ps (11\%), and 22.04 ns (85\%) while $\mathrm{BP}$ in buffer at $87{ }^{\circ} \mathrm{C}$ produces a single lifetime component of $23 \mathrm{~ns}$. Therefore, upon comparing the lifetime of $\mathrm{BP}$ in CT-DNA with that in buffer at $87^{\circ} \mathrm{C}$, it can be concluded that, at such high temperature, $85 \%$ of the DNAbound BP molecules get released to the surrounding buffer.

The observed perturbation of ET from BP to CT-DNA, with the increase in temperature, motivated us to investigate the structural change of the latter associated with such thermal enhancement. Figure 4, a and b, shows the absorption spectra of CT-DNA at different temperatures in the absence and presence of BP, respectively. As evident from the Figure 4a,b, the absorption spectra of CT-DNA do not show any significant change while enhancing the temperature up to $70{ }^{\circ} \mathrm{C}$. The corresponding melting curves of CT-DNA, constructed from the absorbance at $260 \mathrm{~nm}^{24}$ while increasing the temperature up to $90{ }^{\circ} \mathrm{C}$, are shown in the insets of Figure 4, a and b, respectively. As evident from the insets of Figure $4 a, b$, both the curves look alike and do not reach the saturation at $90{ }^{\circ} \mathrm{C}$ (up to which the temperature was enhanced) which suggests that BP-induced structural changes in CT-DNA cannot be manifested through temperature-dependent absorption spectroscopy. Hence we have used the temperature-dependent CD spectroscopy to monitor the BP-induced structural changes in the CT-DNA. Insets of Figure 5, $a$ and $b$, show the temperature-dependent optical rotation of CT-DNA in the absence and presence of BP, respectively. As evident from the insets of Figure $5 \mathrm{a}, \mathrm{b}$, at low temperatures a positive peak around $270 \mathrm{~nm}$ and a negative peak around $245 \mathrm{~nm}$ in the farUV spectrum are in accordance with the average secondary structure of $\mathrm{DNA}^{37}$ and the corresponding UV absorption spectra are dominated by the DNA absorption as shown in the Figure $4 a, b$. Therefore, it is difficult to infer the structural perturbation of CT-DNA in the presence of BP at low 

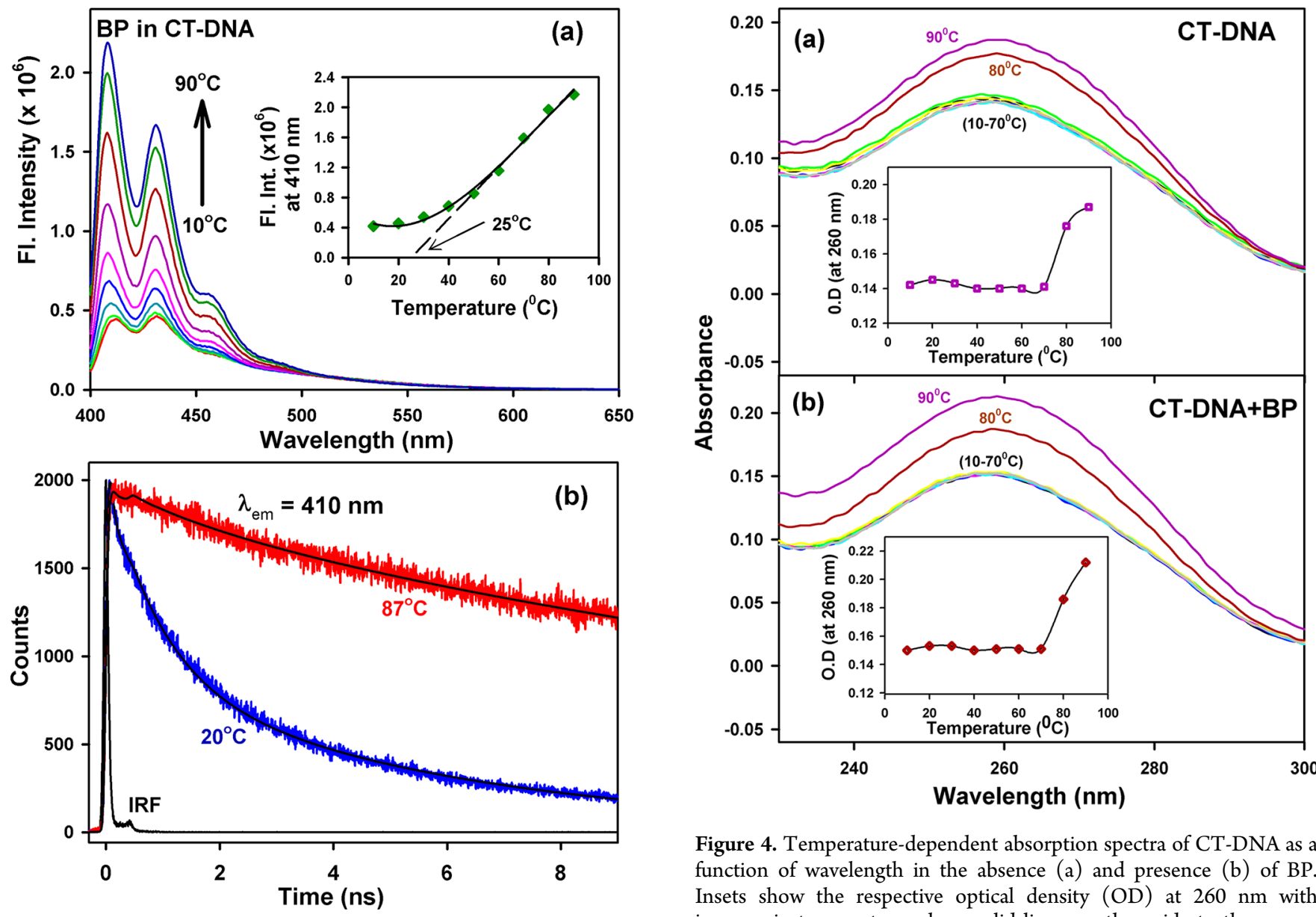

Figure 4. Temperature-dependent absorption spectra of CT-DNA as a function of wavelength in the absence (a) and presence (b) of BP. Insets show the respective optical density (OD) at $260 \mathrm{~nm}$ with increase in temperature where solid lines are the guide to the eye.

Figure 3. (a) Fluorescence spectra of BP in CT-DNA at different temperatures. Inset shows the fluorescence intensity of the same at 410 $\mathrm{nm}$ as a function of temperature and the bold line is the cubic polynomial fit. The broken line is the extrapolated linear fit of the exponentially rising part of the plot, where the intercept at $x$-axis represents the initiation temperature for such rise in the fluorescence intensity. (b) Picosecond-resolved fluorescence transients of the same at $20^{\circ}$ and $87^{\circ} \mathrm{C}$. Excitation wavelength $\left(\lambda_{\mathrm{ex}}=375 \mathrm{~nm}\right)$.

temperatures. It is clear from the insets of Figure $5 \mathrm{a}, \mathrm{b}$ that the peak at $270 \mathrm{~nm}$ is mostly affected by the temperature-induced melting of the DNA. The change in the optical rotation associated with this peak has been monitored to construct the temperature-induced melting of the CT-DNA in the absence and presence of BP, as shown in Figure 5, a and b, respectively. As evident from the figure, the corresponding DNA melting curves do not reach the saturation level at $90{ }^{\circ} \mathrm{C}$, up to which the temperature of the DNA has been raised. Thus, melting temperatures of CT-DNA in the absence and presence of BP

cannot be calculated from the respective melting curves following the standard procedures. However, the temperature at which the melting initiates for either case can be approximated by extrapolating the exponential part of the melting curves on $x$-axis. Though the temperatures are deduced from only three data points in each case, the overall nature of the temperature-dependent change in the optical rotation of CT-DNA at $270 \mathrm{~nm}$ is completely different in the absence and presence of BP, as shown in Figure 5a,b. The uncertainties in the temperature at which the DNA melting initiates, being the same for both the cases (in the absence and presence of BP), have not been considered. The corresponding temperatures, at which DNA melting initiates in the absence and presence of $\mathrm{BP}$, have been found out to be 65 and $59{ }^{\circ} \mathrm{C}$, respectively. The initiation of DNA melting at comparatively lower temperature in the presence of BP is a clear signature of the association of BP with DNA, leading to the weakening of hydrogen bonds

Table 2. Fluorescence Lifetime Components $(\tau)$ of BP in Buffer and upon Interaction with CT-DNA at Different Temperatures along with the Rotational Time Constants $\left(\tau_{\mathrm{r}}\right)^{a}$

\begin{tabular}{|c|c|c|c|c|c|c|c|}
\hline \multirow[b]{2}{*}{ sample } & \multirow[b]{2}{*}{ temp $\left({ }^{\circ} \mathrm{C}\right)$} & \multirow[b]{2}{*}{$\tau_{1}(\mathrm{~ns})$} & \multirow[b]{2}{*}{$\tau_{2}(\mathrm{~ns})$} & \multirow[b]{2}{*}{$\tau_{3}(\mathrm{~ns})$} & \multirow[b]{2}{*}{$\tau_{\mathrm{av}}(\mathrm{ns})$} & \multicolumn{2}{|c|}{ anisotropy } \\
\hline & & & & & & $\tau_{\mathrm{r}}(\mathrm{ns})$ & offset \\
\hline $\mathrm{BP}$ in CT-DNA & 20 & $0.05(40 \%)$ & $0.90(33 \%)$ & $5.61(27 \%)$ & 1.52 & 0.14 & 0.15 \\
\hline & 87 & $0.10(4 \%)$ & $0.80(11 \%)$ & $22.04(85 \%)$ & 18.83 & 0.07 & 0.01 \\
\hline $\mathrm{BP}$ in buffer & 87 & $23.08(100 \%)$ & & & 23.08 & 0.05 & 0.00 \\
\hline
\end{tabular}

${ }^{a}$ Emission wavelength $\left(\lambda_{\mathrm{em}}\right)$ and excitation wavelength $\left(\lambda_{\mathrm{ex}}\right)$ are 410 and $375 \mathrm{~nm}$, respectively. The numbers in parentheses represent relative contributions of the components. $\tau_{\mathrm{av}}$ represents the average lifetime in nanoseconds. Error $\pm 5 \%$. 


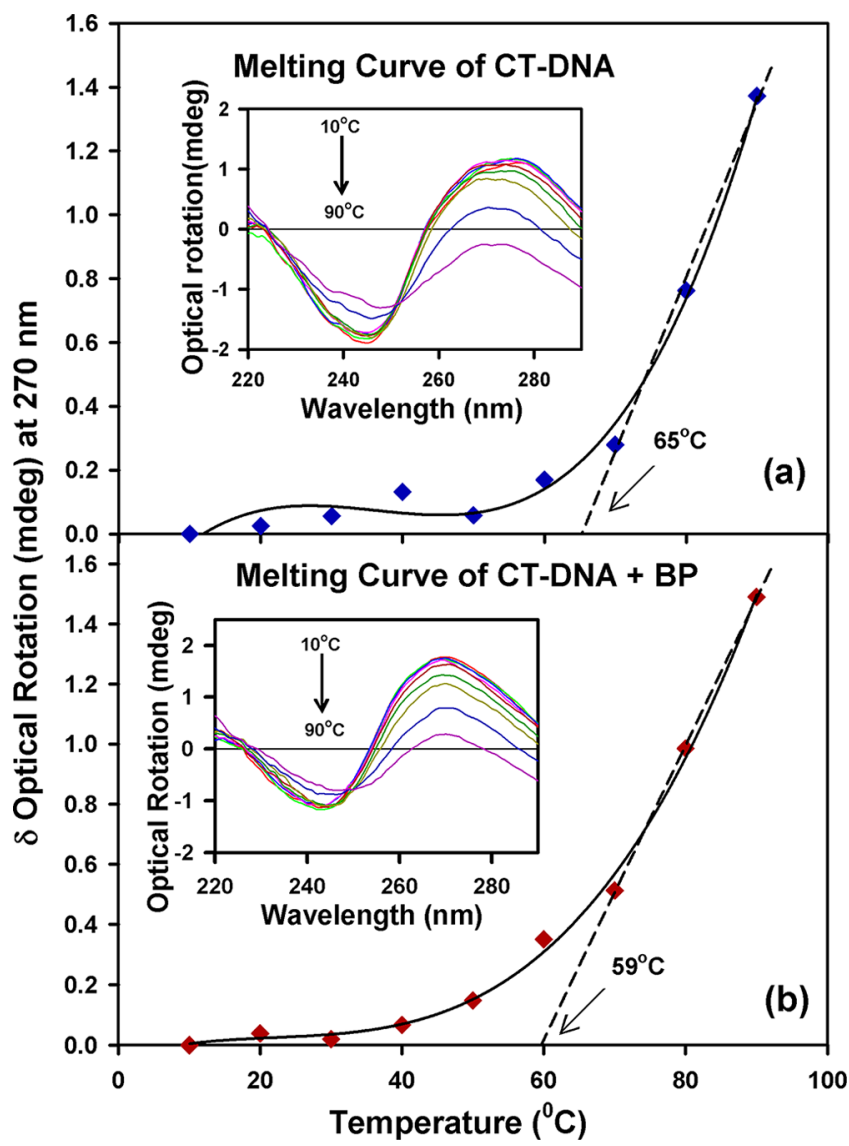

Figure 5. Difference in optical rotation (mdeg) of CT-DNA at $270 \mathrm{~nm}$ with increase in temperature in the absence (a) and presence (b) of BP. Insets show the respective temperature-dependent optical rotation of the CT-DNA as a function of wavelength. Solid lines are the cubic polynomial fit. The broken lines are the extrapolated linear fits where the intercepts at $x$-axis represent the initiation temperature of the corresponding melting processes.

between the two DNA strands. Thus, lower thermal energy is required to initiate DNA melting in the presence of $\mathrm{BP}$ compared to that in its absence. Here, it has to be noted that the initiation temperature observed for the enhancement in emission intensity of BP in CT-DNA (Figure 3a inset) is much lower compared to that of BP-assisted DNA melting, which signifies that perturbation in ET from BP to CT-DNA initiates at some lower temperature prior to the DNA melting. Such perturbation in ET before the onset of DNA melting can arise due to some changes in the orientation of DNA bound BP molecules, interfering in the ET pathway.

For better understanding of the fate of BP with the melting of DNA, the fluorescence anisotropies of BP have been monitored in the presence of DNA at $20{ }^{\circ} \mathrm{C}$ and at DNA melting temperature $\left(\sim 87^{\circ} \mathrm{C}\right)$, as shown in Figure 6 , a and b, respectively. The rotational time constants $\left(\tau_{\mathrm{r}}\right)$ of BP in DNA have been calculated from the respective fluorescence anisotropies and have been compared with that of BP in phosphate buffer at $87^{\circ} \mathrm{C}$ (inset of Figure $6 \mathrm{~b}$ ). The values of the respective $\tau_{\mathrm{r}}$ have been tabulated in Table 2 . The fluorescence aniosotropy of BP in CT-DNA at $20{ }^{\circ} \mathrm{C}$ produces a $\tau_{\mathrm{r}}$ value of $140 \mathrm{ps}$ which corresponds to the rotational motion of the probe $\mathrm{BP}$ in the DNA, along with a residual offset of 0.15 . The origin of such offset is due to the overall motion of the DNA which does not decay within the experimental time

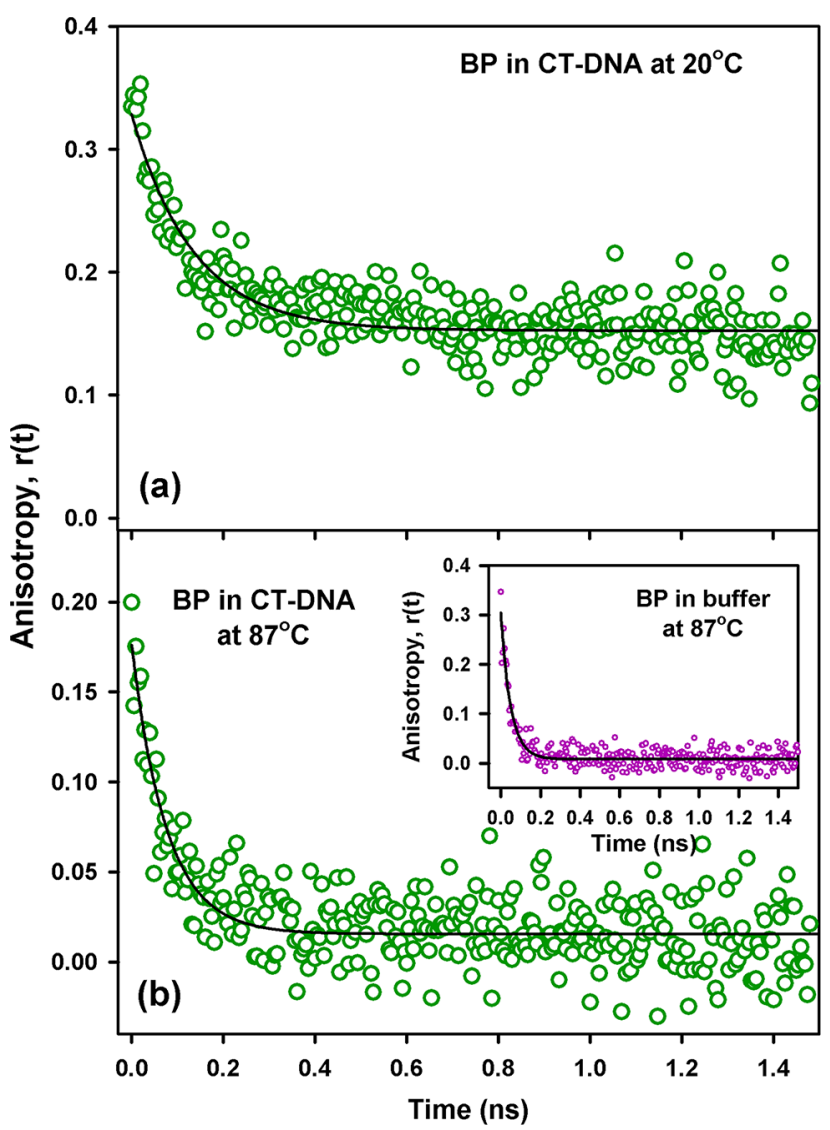

Figure 6. Fluorescence anisotropy of BP in CT-DNA at (a) $20^{\circ} \mathrm{C}$ and (b) $87^{\circ} \mathrm{C}$ and in $50 \mathrm{mM}$ phosphate buffer at $87^{\circ} \mathrm{C}$ (inset of b). Solid lines indicate exponential fitting of the experimental data points.

window. Using the time-resolved fluorescence anisotropy study, Ghiggino and co-workers ${ }^{38}$ have documented the dynamics of energy transfer in multiporphyrin functionalized dendrimers where they observed a fast decay $(\sim 80 \mathrm{ps})$ in the anisotropy profile with a residual offset similar to our observation. As shown in Figure 6 and Table 2, the rotational time constant of $\mathrm{BP}$ in CT-DNA decreases from 140 to $70 \mathrm{ps}$ and the residual offset becomes negligible as the DNA reaches its melting temperature. The $\tau_{\mathrm{r}}$ value calculated for BP in CT-DNA at 87 ${ }^{\circ} \mathrm{C}$ is close to that calculated for BP in buffer at the same temperature, indicating the release of $\mathrm{BP}$ to buffer with the melting of DNA. Here it has to be noted that the solubility of $\mathrm{BP}$ in aqueous medium at low temperatures being extremely low, experiments could not be performed with the aqueous solution of BP at low temperatures. However, the solubility of the same in aqueous buffer medium increases from $10^{-8}$ to $10^{-7}$ $\mathrm{M}$, with enhancement in temperature from 20 to $87^{\circ} \mathrm{C}$. Therefore, with the dilute aqueous solution of BP at $87^{\circ} \mathrm{C}$ in $0.05 \mathrm{M}$ phosphate buffer, anisotropy experiments have been performed which gives the rotational time constant of $50 \mathrm{ps}$ without any offset. The higher solubility of BP in buffer at elevated temperature further supports the release of $\mathrm{BP}$ from DNA at the DNA melting temperature around $87^{\circ} \mathrm{C}$. Thus, unlike ethidium (Et), a well-known DNA intercalator which significantly remains bound to single-stranded (ss) DNA upon DNA melting producing a characteristic lifetime component ${ }^{39}$ of about $18 \mathrm{~ns}$ and a DNA minor groove binder, Hoechst 33258 (H258), which also remains associated with DNA at high temperatures, ${ }^{37} \mathrm{BP}$ almost completely dissociates from 
DNA at high temperature (beyond the melting temperature of DNA) with no signature of binding to ss DNA.

After investigating ET reaction from BP to CT-DNA in a temperature-dependent manner, we further investigated such interaction with another biological macromolecule, human serum albumin (HSA), as carcinogens are known to interact not only with DNAs but also with proteins. ${ }^{14,40}$ Figure 7 a
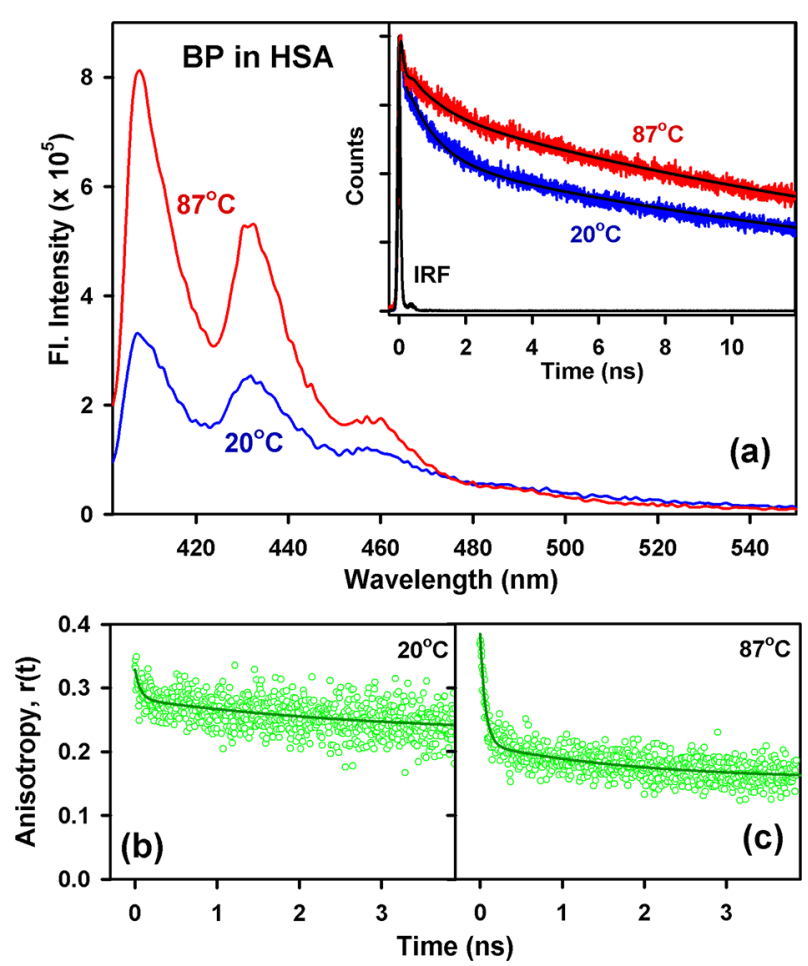

Figure 7. (a) Fluorescence spectra of BP in HSA at 20 and $87^{\circ} \mathrm{C}$; inset shows the corresponding time-resolved fluorescence transients. Fluorescence anisotropy of the same at (b) $20^{\circ} \mathrm{C}$ and (c) $87^{\circ} \mathrm{C}$. Solid lines indicate exponential fitting of the experimental data points.

shows the emission spectra of BP in HSA at 20 and $87^{\circ} \mathrm{C}$ upon excitation with UVA radiation. The relatively lower emission intensity of BP at the aggregate peak around $490 \mathrm{~nm}$ compared to the monomer peaks at 410,430, and $455 \mathrm{~nm}$, similar to our observation for BP upon complexation with CT-DNA (Figure $3 a)$, is again a clear evidence of association between the carcinogen and HSA. As evident from Figure 7a, the emission intensity of BP in the presence of HSA also enhances with the increase in temperature from 20 to $87{ }^{\circ} \mathrm{C}$ similar to that observed for the BP-CT-DNA complex. However, the extent of enhancement in the emission intensity of BP in the presence of HSA is much lower compared to that in the presence of CTDNA. Therefore, with the increase in temperature the ET pathway of BP in the presence of HSA gets perturbed to some lower extent, compared to our previous observation in the presence of CT-DNA. Figure 7a inset shows the time-resolved fluorescence transients of BP-HSA complex at 20 and $87{ }^{\circ} \mathrm{C}$ while exciting with UVA radiation. The corresponding lifetime components have been tabulated in Table 3. The ultrafast time components of 70 and 870 ps in the lifetime of BP upon association with HSA strongly corroborate with the ET components observed in the fluorescence transients of $\mathrm{BP}$ while participating in ET reaction with $\mathrm{BQ}$ and DNA, mentioned above and thus have been attributed to the UVA radiation induced ET from BP to HSA. Amino acids in HSA possessing lower oxidation potential compared to BP can be involved in such ET reaction from BP to HSA. For example, the oxidation potential of tryptophan in HSA being lower $(\sim 1 \mathrm{~V})^{41}$ than that of BP $(\sim 1.18 \mathrm{~V}){ }^{42}$ supports the flow of electrons from BP to HSA in the observed ET reaction between the two. In contrast to our previous observation in the presence of CTDNA, the contributions of ET components of 70 and 870 ps in the fluorescence transient of BP in the presence of HSA are found to get decreased from 39 to $37 \%$ and from 23 to $13 \%$, respectively, with the similar increase in temperature from 20 to $87^{\circ} \mathrm{C}$. The major contribution of the ET components in the fluorescence transient of BP in HSA even at $87{ }^{\circ} \mathrm{C}$, where the protein gets significantly unfolded, ${ }^{43}$ suggests that $\mathrm{BP}$ remains bound to unfolded HSA unlike CT-DNA at high temperature. For further confirmation regarding the association of BP with unfolded HSA, the fluorescence anisotropy of BP at $87^{\circ} \mathrm{C}$ has been compared with that at $20^{\circ} \mathrm{C}$ as shown in Figure $7 \mathrm{~b}, \mathrm{c}$. At both the temperatures 20 and $87{ }^{\circ} \mathrm{C}$, the anisotropy exhibits biexponential decay with a residual offset of 0.22 and 0.16 , respectively. The corresponding $\tau_{\mathrm{r}}$ values are tabulated in Table 3. The offset observed in the BP-HSA complex at 20 and 87 ${ }^{\circ} \mathrm{C}$ is due to the overall motion of the protein HSA which does not decay within the experimental time window. The ultrafast time component $\sim 70$ ps with a huge offset, observed in the temporal decays of the rotational anisotropy of BP bound to $\mathrm{HSA}$ at 20 and $87{ }^{\circ} \mathrm{C}$, is comparable to the electronic energy transfer component in the anisotropy profile of multiporphyrin functionalized dendrimers ${ }^{38}$ mentioned before. The presence of electronic energy transfer component along with a significant residual offset in the rotational anisotropy of BP in unfolded HSA at $87{ }^{\circ} \mathrm{C}$ confirms the association of BP with unfolded HSA unlike denatured CT-DNA. The association of BP with unfolded HSA strongly corroborates with one of our earlier studies, ${ }^{43}$ where it has been shown that an extremely hydrophobic probe can reside in the subdomain IIIA of the protein even at its thermally unfolded states.

Our investigation on the ET reaction from BP to organic molecules and biological macromolecules (shown in Scheme la,b) has been further extended with inorganic zinc oxide $(\mathrm{ZnO})$ nanorods (NRs). The purpose of this study is to probe whether ET from $\mathrm{BP}$ to $\mathrm{ZnO} \mathrm{NRs}$ is achieved in terms of

Table 3. Fluorescence Lifetime Components $(\tau)$ of BP upon Interaction with HSA at Different Temperatures along with the Rotational Time Constants $\left(\tau_{\mathrm{r}}\right)^{a}$

\begin{tabular}{|c|c|c|c|c|c|c|c|c|}
\hline \multirow[b]{2}{*}{ sample } & \multirow[b]{2}{*}{ temp $\left({ }^{\circ} \mathrm{C}\right)$} & \multirow[b]{2}{*}{$\tau_{1}(\mathrm{~ns})$} & \multirow[b]{2}{*}{$\tau_{2}(\mathrm{~ns})$} & \multirow[b]{2}{*}{$\tau_{3}(\mathrm{~ns})$} & \multirow[b]{2}{*}{$\tau_{\mathrm{av}}(\mathrm{ns})$} & \multicolumn{3}{|c|}{ anisotropy } \\
\hline & & & & & & \multicolumn{2}{|c|}{$\tau_{\mathrm{r}}(\mathrm{ns})$} & offset \\
\hline $\mathrm{BP}$ in HSA & 20 & $0.07(39 \%)$ & $0.87(23 \%)$ & $19.09(38 \%)$ & 7.48 & $0.07(46 \%)$ & $2.99(54 \%)$ & 0.22 \\
\hline & 87 & $0.07(37 \%)$ & $0.90(13 \%)$ & $20.12(50 \%)$ & 10.20 & $0.06(76 \%)$ & $1.89(24 \%)$ & 0.16 \\
\hline
\end{tabular}

${ }^{a}$ Emission wavelength $\left(\lambda_{\mathrm{em}}\right)$ and excitation wavelength $\left(\lambda_{\mathrm{ex}}\right)$ are 410 and $375 \mathrm{~nm}$, respectively. The numbers in parentheses represent relative contributions of the components. $\tau_{\text {av }}$ represents the average lifetime in nanoseconds. Error $\pm 5 \%$. 
photocurrent. By making the use of the basic working principle of a dye-sensitized solar cell, we have designed a photodevice, as schematically shown in Scheme 1c. Figure $8 \mathrm{a}$, left inset,
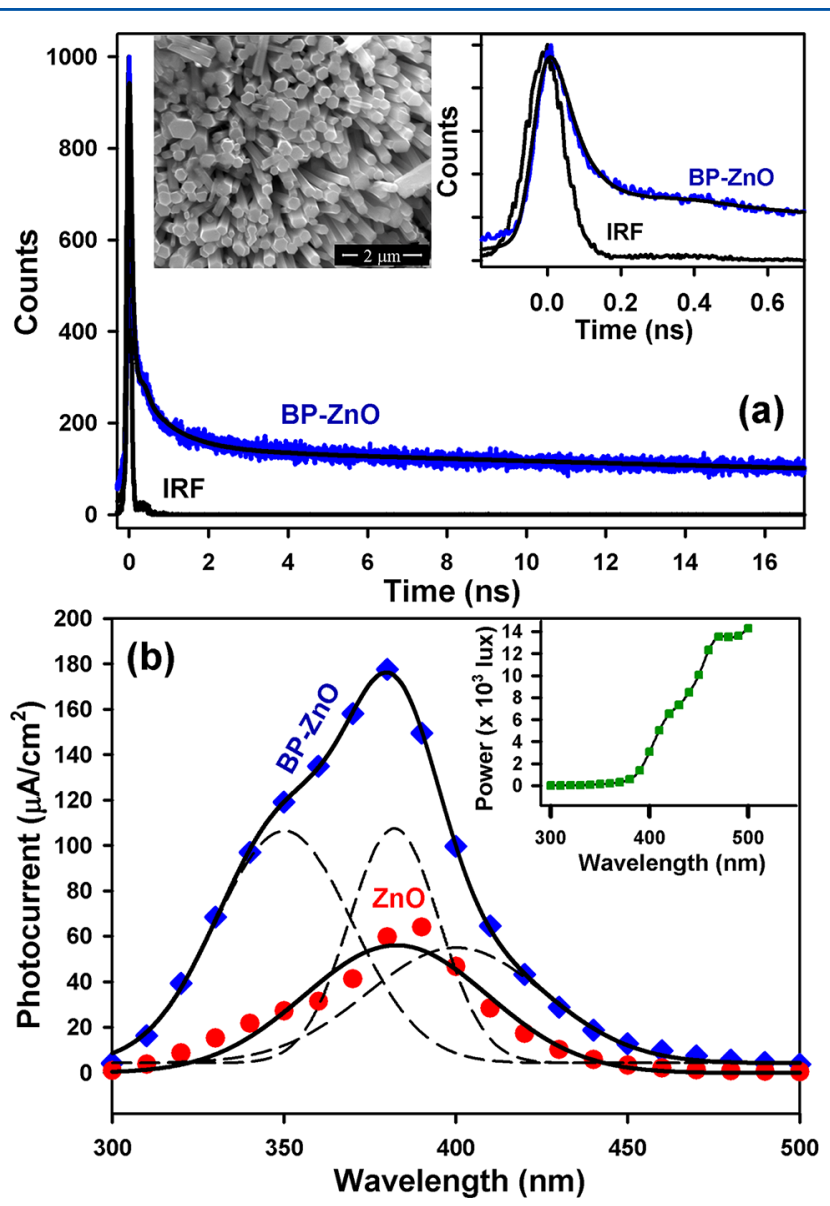

Figure 8. (a) Time-resolved fluorescence transient of $\mathrm{BP}-\mathrm{ZnO}$ complex in thin film; the right inset shows the same in a narrow time window, while the left inset shows the scanning electron micrographs (SEM images) of ZnO NRs. (b) Wavelength-dependent photocurrent obtained from $\mathrm{ZnO}$ NR fabricated photodevices in the presence and absence of BP. Bold lines represent the Gaussian fits of the respective plots, and the broken lines represent the deconvoluted plots of $\mathrm{BP}-$ $\mathrm{ZnO}$ complex having peaks at 350,382, and $400 \mathrm{~nm}$. Inset shows the variation of power over the same wavelength range where the bold line is the guide to the eye.

shows the scanning electron micrographs (SEM images) of $\mathrm{ZnO}$ NRs. Morphological characterization by SEM (Figure 8a, left inset) indicates the formation of arrays of $\mathrm{ZnO}$ NRs with a preferential growth along the polar facets [002 direction] of the hexagonal wurtzite crystal. The NRs growing perpendicular to the substrate are nearly uniform in length $(\sim 3 \mu \mathrm{m})$ and possess a characteristic hexagonal cross section with diameter in the range of $180 \mathrm{~nm}$. For the investigation of UVA radiation induced ET reaction between $\mathrm{BP}$ monomers and $\mathrm{ZnO}$ NRs, picosecond-resolved fluorescence transient of $\mathrm{BP}$ has been monitored at $410 \mathrm{~nm}$ on thin film in the presence of $\mathrm{ZnO} N R$ as shown in Figure 8a and it is fitted with the values given in Table 4. As evident from Figure $8 \mathrm{a}$ and Table 4, ultrafast components of 50 and 880 ps appear in the fluorescence transient of $\mathrm{BP}$ in the presence of $\mathrm{ZnO}$ NRs, along with a long component ( $\sim 39 \mathrm{~ns})$ comparable to the lifetime of BP in degassed benzene. ${ }^{13}$ To differentiate the ultrafast component of
Table 4. Lifetime Components of BP monitored at $410 \mathrm{~nm}$ $\left(\lambda_{\mathrm{em}}\right)$ on Thin Film in the Presence of $\mathrm{ZnO} \mathrm{NRs}^{a}$

\begin{tabular}{|c|c|c|c|}
\hline sample & $\tau_{1}(\mathrm{~ns})$ & $\tau_{2}(\mathrm{~ns})$ & $\tau_{3}(\mathrm{~ns})$ \\
\hline $\mathrm{ZnO} \mathrm{NR}$ anchored $\mathrm{BP}$ & $0.05(89 \%)$ & $0.88(6 \%)$ & $39.64(5 \%)$ \\
\hline
\end{tabular}

50 ps from IRF, the fluorescence transient of $\mathrm{ZnO} \mathrm{NR}$ anchored BP is shown over a narrow time window of $0.7 \mathrm{~ns}$ in Figure $8 \mathrm{a}$, right inset. The ultrafast components in the fluorescence transient of $\mathrm{BP}$ in the presence of $\mathrm{ZnO}$ NRs being comparable with the ET components observed in the fluorescence transients of the same while undergoing ET reaction with organic molecules and biological macromolecules (mentioned before) validates the ET from BP to $\mathrm{ZnO}$ NRs. Here it has to be noted that the observed ET components in the lifetime of BP in different systems are similar but they are exactly not the same and this difference can be attributed to the difference in redox properties of the systems. Moreover, the picosecond resolved lifetime measurements were all done in time-correlated single-photon-counting (TCSPC) setup having instrument response function (IRF) of 80 ps and hence very fine variations (in femtosecond time scale) of the ET process are beyond the resolution of the used setup. The ET from BP to $\mathrm{ZnO} \mathrm{NRs}$ has been further confirmed by monitoring the flow of electrons in terms of photocurrent. Figure $8 \mathrm{~b}$ shows the wavelength-dependent variation in photocurrent, monitored in $\mathrm{ZnO}$ NR fabricated photodevice in the presence and absence of $\mathrm{BP}$. As shown by the broken lines in Figure $8 \mathrm{~b}$, the photocurrent versus wavelength curve in the presence of $\mathrm{BP}$ can be deconvoluted into three characteristic peaks at 350, 382, and $400 \mathrm{~nm}$ similar to the absorption peaks of $\mathrm{BP}^{44}$ while that in the absence of $\mathrm{BP}$ produces a single peak corresponding to the absorption peak of $\mathrm{ZnO}$ at $382 \mathrm{~nm}$. The enhanced photocurrent obtained in the presence of $\mathrm{BP}$ from $\mathrm{ZnO} \mathrm{NR}$ fabricated photodevice confirms the role of $\mathrm{BP}$ as the photosensitizer. Inset of Figure $8 \mathrm{~b}$ indicates that in the wavelength range of $300-380 \mathrm{~nm}$, power remains almost constant while there is a constant enhancement in photocurrent, suggesting that the photocurrent measured is solely dependent on the flow of electrons irrespective of the power.

\section{CONCLUSION}

Electron-transfer (ET) reactions are well-known for their importance in DNA damage and cancer biochemistry. In the present study, we explored the strong affinity of the carcinogen benzo $[a]$ pyrene $(\mathrm{BP})$ to donate electrons to different class of molecules like $p$-benzoquinone (BQ), biological macromolecules like calf-thymus DNA and human serum albumin (HSA), and inorganic nano structures like zinc oxide $(\mathrm{ZnO})$ nanorods (NRs). While steady-state and time-resolved fluorescence spectroscopy results reveal the quenching of the emission of $\mathrm{BP}$ in the presence of organic molecules, biological macromolecules, and nano structures, CD spectroscopy results monitoring the BP-induced structural changes in the CTDNA and $\mathrm{ZnO}-\mathrm{NR}$ based photodevice confirm the chargetransfer reaction from BP by directly monitoring the flow of electrons in terms of photocurrent. Our ultrafast electron transfer studies from BP to four different types of molecules suggest $\mathrm{BP}$ as a strong electron donor which can be considered as one of its vital characteristics responsible for its carcinogenic 
activity. Therefore, our work hints that the ET pathway from BP can be targeted to prevent BP-mediated carcinogenesis. It has to be noted that carcinogenesis of BP may involve other modes of interaction with biological macromolecules apart from ET which our objective does not include. We emphasize one of the key aspects of BP which can assist in further research on this carcinogen.

\section{AUTHOR INFORMATION}

\section{Corresponding Author}

*E-mail: skpal@bose.res.in. Fax: 913323353477.

\section{Notes}

The authors declare no competing financial interest.

\section{ACKNOWLEDGMENTS}

S.B. and S.S. thank UGC (India) for fellowships. We thank DST (India) for financial grants (DST/TM/SERI/2k11/103).

\section{REFERENCES}

(1) Phillips, D. H. Fifty Years of Benzo(a)pyrene. Nature 1983, 303, 468-472.

(2) Phillips, D. H. Polycyclic Aromatic Hydrocarbons in the Diet. Mutat. Res. 1999, 443, 139-147.

(3) Ling, H.; Sayer, J. M.; Plosky, B. S.; Yagi, H.; Boudsocq, F.; Woodgate, R.; Jerina, D. M.; Yang, W. Crystal Structure of a Benzo[a]pyrene Diol Epoxide Adduct in a Ternary Complex with a DNA Polymerase. Proc. Natl. Acad. Sci. U.S.A. 2004, 101, 2265-2269.

(4) Alam, S.; Conway, M. J.; Chen, H. S.; Meyers, C. The Cigarette Smoke Carcinogen Benzo[a]pyrene Enhances Human Papillomavirus Synthesis. J. Virol. 2008, 82, 1053-1058.

(5) Dutta, K.; Ghosh, D.; Nazmi, A.; Kumawat, K. L.; Basu, A. A Common Carcinogen Benzo[a]pyrene Causes Neuronal Death in Mouse via Microglial Activation. PloS One 2010, 5, 1-14.

(6) Shimizu, Y.; Nakatsuru, Y.; Ichinose, M.; Takahashi, Y.; Kume, H.; Mimura, J.; Kuriyama, Y. F.; Ishikawa, T. Benzo[a]pyrene Carcinogenicity is Lost in Mice Lacking the Aryl Hydrocarbon Receptor. Proc. Natl. Acad. Sci. U.S.A. 2000, 97, 779-782.

(7) Denissenko, M. F.; Pao, A.; Tang, M. S.; Pfeifer, G. P. Preferential Formation of Benzo[a]pyrene Adducts at Lung Cancer Mutational Hotspots in P53. Science 1996, 274, 430-432.

(8) Kapitulnik, J.; Levin, W.; Conney, A. H.; Yagi, H.; Jerina, D. M. Benzo[a]pyrene 7,8-dihydrodiol is More Carcinogenic than Benzo[a]pyrene in New Born Mice. Nature 1977, 266, 378-380.

(9) Eling, T. E.; Thompson, D. C.; Foureman, G. L.; Curtis, J. F.; Hughes, M. F. Prostaglandin H Synthase and Xenobiotic Oxidation. Annu. Rev. Pharmacol. Toxicol. 1990, 30, 1-45.

(10) Wilk, M.; Girke, W. Reactions Between Benzo[a]pyrene and Nucleo bases by One-Electron Oxidation. J. Natl. Cancer Inst. 1972, 49, 1585-5197.

(11) Wan, C.; Fiebig, T.; Kelley, S. O.; Treadway, C. R.; Barton, J. K.; Zewail, A. H. Femtosecond Dynamics of DNA-Mediated Electron Transfer. Proc. Natl. Acad. Sci. U.S.A. 1999, 96, 6014-6019.

(12) Nguyena, J.; Maa, Y.; Luoa, T.; Bristowb, R. G.; Jaffrayc, D. A.; Lua, Q. B. Direct Observation of Ultrafast-Electron-Transfer Reactions Unravels High Effectiveness of Reductive DNA Damage. Proc. Natl. Acad. Sci. U.S.A. 2011, 108, 11778-11783.

(13) Geacintov, N. E.; Prusik, T.; Khosrofian, J. M. Properties of Benzopyrene-DNA Complexes Investigated by Fluorescence and Triplet Flash Photolysis Techniques. J. Am. Chem. Soc. 1976, 98, 6444-6452.

(14) Skipper, P. L.; Tannenbaum, S. R. Protein Adducts in the Molecular Dosimetry of Chemical Carcinogens. Carcinogenesis 1990, 11, 507-518.

(15) Kure, E. H.; Andreassen, A.; Ovrebo, S.; Grzybowska, E.; Fiala, Z.; Strozyk, M.; Chorazy, M.; Haugen, A. Benzo(a)pyrene-Albumin Adducts in Humans Exposed to Polycyclic Aromatic Hydrocarbons in an Industrial Area of Poland. Occup. Environ. Med. 1997, 54, 662-666.
(16) Srinivasan, B. N.; Fujimori, E. Benzo[a]pyrene-Serum: Albumin/cysteine Interactions: Fluorescene and Electron Spin Resonance Studies. Chem. Biol. Interact. 1979, 28, 1-15.

(17) Brenner, D. J.; Doll, R.; Goodhead, D. T.; Hall, E. J.; Land, C. E.; Little, J. B.; Lubin, J. H.; Preston, D. L.; Preston, R. J.; Puskin, J. S.; Ron, E.; Sachs, R. K.; Samet, J. M.; Setlow, R. B.; Zaider, M. Cancer Risks Attributable to Low doses of Ionizing radiation: Assessing What We Really Know. Proc. Natl. Acad. Sci. U.S.A. 2003, 100, 1376113766.

(18) Land, C. E.; Boice, J. D.; Shore, R. E.; Norman, J. E.; Tokunaga, M. Breast Cancer Risk From Low-Dose Exposures to Ionizing Radiation: Results of Parallel Analysis of Three Exposed Populations of Women. J. Natl. Cancer Inst. 1980, 65, 353-376.

(19) Kawanishi, S.; Hiraku, Y.; Oikawa, S. Mechanism of GuanineSpecific DNA Damage by Oxidative Stress and its Role in Carcinogenesis and Aging. Mutat. Res. Rev. Mutat. 2001, 488, 65-76.

(20) Toyooka, T.; Ibuki, Y.; Koike, M.; Ohashi, N.; Takahashi, S.; Goto, R. Coexposure to Benzo[a]pyrene Plus UVA Induced DNA Double Strand Breaks: Visualization of Ku Assembly in the Nucleus Having DNA Lesions. Biochem. Biophys. Res. Commun. 2004, 322, 631-636.

(21) Toyooka, T.; Ibuki, Y.; Takabayashi, F.; Goto, R. Coexposure to Benzo[a]pyrene and UVA Induces DNA Damage: First proof of Double-Strand Breaks in a Cell-Free System. Environ. Mol. Mutagen. 2006, 47, 38-47.

(22) Kang, Q.; Chen, Y.; Li, C.; Cai, Q.; Yao, S.; Grimes, C. A. Calabresi, P. A Photoelectrochemical Immunosensor for Benzo[a]pyrene Detection Amplified by Bifunctional Gold Nanoparticles. Chem. Commun. 2011, 47, 12509-12511.

(23) Atal, N.; Saradhi, P. P.; Mohanty, P. Inhibition of the Chloroplast Photochemical Reactions by Treatment of Wheat Seedlings with Low Concentrations of Cadmium: Analysis of Electron Transport Activities and Changes in Fluorescence Yield. Plant Cell Physiol. 1991, 32, 943-951.

(24) Douki, T. Effect of Denaturation on the Photochemistry of Pyrimidine Bases in Isolated DNA. J. Photochem. Photobiol. B 2006, 82, $45-52$.

(25) Pal, S. K.; Zhao, L.; Zewail, A. H. Water at DNA Surfaces: Ultrafast Dynamics in Minor Groove Recognition. Proc. Natl. Acad. Sci U.S.A.. 2003, 100, 8113-8118.

(26) Khan, S. N.; Islam, B.; Khan, A. U. Probing Midazoan Interaction with Human Serum Albumin and its Effect on Structural State of Protein. IJIB 2007, 1, 102-112.

(27) Sarkar, S.; Makhal, A.; Bora, T.; Lakshman, K.; Singha, A.; Dutta, J.; Pal, S. K. Hematoporphyrin-ZnO Nanohybrids: Twin Applications in Efficient Visible-Light Photocatalysis and DyeSensitized Solar Cells. ACS Appl. Mater. Interfaces 2012, 4, 7027-7035.

(28) Sarkar, S.; Makhal, A.; Lakshman, K.; Bora, T.; Dutta, J.; Pal, S. K. Dual-Sensitization via Electron and Energy Harvesting in CdTe Quantum Dots Decorated ZnO Nanorod-Based Dye-Sensitized Solar Cells. J. Phys. Chem. C 2012, 116, 14248-14256.

(29) O'Connor, D. V.; Philips, D. Time Correlated Single Photon Counting; Academic Press: London, 1984.

(30) Lakowicz, J. R. Principles of Fluorescence Spectroscopy; Kluwer Academic/Plenum: New York, 1999.

(31) Cooper, C. D.; Naff, W. T.; Compton, R. N. Negative Ion Properties of p-Benzoquinone: Electron Affinity and Compound States. J. Chem. Phys. 1975, 63, 2752-2757.

(32) Beck, S. C.; Cramb, D. T. Condensed Phase Dispersive Interactions of Benzo $[a]$ pyrene with Various Solvents and with DNA: A Twist on Solvatochromism. J. Phys. Chem. B 2000, 104, 2767-2774.

(33) Wells, T. A.; Losi, A.; Dai, R.; Scott, P.; Park, S. M.; Golbeck, J.; Song, P. S. Electron Transfer Quenching and Photoinduced EPR of Hypericin and the Ciliate Photoreceptor Stentorin. J. Phys. Chem. A 1997, 101, 366-372.

(34) Leland, B. A.; Joran, A. D.; Felker, P. M.; Hopfield, J. J.; Zewail, A. H.; Dervan, P. B. Picosecond Fluorescence Studies on Intramolecular Photochemical Electron Transfer in Porphyrins Linked to 
Quinones at Two Different Fixed Distances. J. Phys. Chem. 1985, 89, 5571-5573.

(35) Chen, G.; Cooks, R. G. Electron Affinities of Polycyclic Aromatic Hydrocarbons Determined by the Kinetic Method. J. Mass. Spectrom. 1995, 30, 1167-1173.

(36) Sutherland, J. C.; Griffin, K. P. Absorption Spectrum of DNA for Wavelengths Greater than $300 \mathrm{~nm}$. Radiat. Res. 1981, 86, 399-410.

(37) Banerjee, D.; Pal, S. K. Direct Observation of Essential DNA Dynamics: Melting and Reformation of the DNA Minor Groove. J. Phys. Chem. B 2007, 111, 10833-10838.

(38) Yeow, E. K. L.; Ghiggino, K. P.; Reek, J. N. H.; Crossley, M. J.; Bosman, A. W.; Schenning, A. P. H. J.; Meijer, E. W. The Dynamics of Electronic Energy Transfer in Novel Multiporphyrin Functionalized Dendrimers: A Time-Resolved Fluorescence Anisotropy Study. J. Phys. Chem. B 2000, 104, 2596-2606.

(39) Banerjee, S.; Bhowmik, D.; Verma, P. K.; Mitra, R. K.; Sidhhanta, A.; Basu, G.; Pal, S. K. Ultrafast Spectroscopic Study on Caffeine Mediated Dissociation of Mutagenic Ethidium from Synthetic DNA and Various Cell Nuclei. J. Phys. Chem. B 2011, 115, 1477614783.

(40) Ketterer, B. Interactions Between Carcinogens and Proteins. Br. Med. Bull. 1980, 36, 71-78.

(41) Marme, N.; Knemeyer, J. P.; Sauer, M.; Wolfrum, J. Inter- and Intramolecular Fluorescence Quenching of Organic Dyes by Tryptophan. Bioconjugate Chem. 2003, 14, 1133-1139.

(42) Keskin, E.; Yardım, Y.; Senturk, Z. Voltammetry of Benzo[a]pyrene in Aqueous and Nonaqueous Media: Adsorptive Stripping Voltammetric Determination at Pencil Graphite Electrode. Electroanalysis 2010, 22, 1191-1199.

(43) Sinha, S. S.; Mitra, R. K.; Pal, S. K. Temperature-Dependent Simultaneous Ligand Binding in Human Serum Albumin. J. Phys. Chem. B 2008, 112, 4884-4891.

(44) Larsen, J. S.; Waluk, J.; Eriksson, S.; Thulstrup, E. W. Electronic States of Benzo[a]pyrene. Linear and Magnetic Circular Dichroism, Polarized Fluorescence, and Quantum Chemical Calculations. J. Am. Chem. Soc. 1992, 114, 1942-1949. 